\title{
Predicting Body Weight of Ethiopian Indigenous Chicken Populations from Morphometric Measurements
}

\begin{abstract}
Fikrineh Negash ${ }^{1, a, *}$
${ }^{1}$ Adami Tulu Agricultural Research Centre, P. O. Box 35, Batu, Ethiopia

*Corresponding author

A R T I C L I N F O A B S T R A C T

Research Article

Received : 27/11/2020

Accepted : 29/01/2021

Keywords:

Linear body measurements

Linear regression

Model validation

Multicollinearity

Prediction equation

The purpose of this study was to estimate the relationship between body weight (BW) and morphometric measurements of Ethiopian indigenous chicken populations and to develop prediction equations used to estimate BW from body measurements. A total of 621 chickens comprising 134 males and 487 females reared under smallholder management conditions were used for the study. Body weight and morphometric measurements including body length (BL), chest circumference (CC), shank length (SL), and shank circumference (SC) were taken using a hanging scale and a textile measuring tape, respectively. The relationship between BW and morphometric measurements was determined using Pearson's correlation coefficients $(r)$ and stepwise multiple regression analyses. Descriptive statistics indicated that male birds were heavier than female birds. Correlation results revealed that body weight was significantly and strongly correlated with SL $(r=0.76)$ in both sexes, and moderately correlated with SC $(r=0.69)$, BL $(r=0.67)$, and CC $(r=0.52)$ in male birds, BL $(r=0.68)$ and SC $(r=0.59)$ in female birds. Compared to other measurements, SL best predicted BW in both male and female birds, with coefficients of determination $\left(R^{2}\right)=0.58$. Combining SL with other body measurements (BL, CC, and SC) generally improved the predictive power of the equation. Thus, multiple regression equations that included a combination of the four linear body measurements are more suitable for predicting BW of Ethiopian indigenous chicken populations.
\end{abstract}

fikrineh2010@gmail.com

(iD) http://orcid.org/0000-0003-1170-1833 |

This work is licensed under Creative Commons Attribution 4.0 International License

\section{Introduction}

Body weight (BW) is one of the most important attributes of farm animals. A better understanding of BW and its changes is important in evaluating growth performance, feed efficiency, responses of animals to various environmental conditions and production systems, determination of feed requirements, and making economic decisions (Momoh and Kershima, 2008; Assan, 2013; Lukuyu et al., 2016; Deribe et al., 2018). The most common and direct way to estimate an animal's BW is to weigh it using a calibrated electronic or mechanical weighing scale. However, this method poses a challenge for smallholder farmers in rural areas because the weighing scale may not be readily available (Lukuyu et al., 2016). Lack of technical skills may also be a constraint to accurately weighing and assessing animals (Adeyinka and Mohammed, 2006). An alternative and the simplest method is to measure body parts and relate the measurements to BW (Latshaw and Bishop, 2001; Assan, 2013). Although it is not more accurate compared to direct measurement of live weight (Sowande and Sobola, 2008), body measurements have been used to estimate BW in poultry and livestock species.

Elsewhere, a strong relationship between BW and chest circumference (Semakula et al., 2011), shank length (Alabi et al., 2012; Ukwu et al., 2014), shank circumference (Alabi et al., 2012), and body length (Egena et al., 2014) have been reported for indigenous chicken populations. These studies indicated that these body measurements are useful and reliable predictors of BW in chickens. However, the predictive equation developed for a particular breed may not apply to chickens found under different production and management conditions. There is a general agreement that the estimation of BW from the animal's body measurements can be influenced by several factors, including breed, sex, environment, and production system. Body measurements of the same breed in different environments and production systems may not be similar (Assan, 2013). Therefore, specific models are needed for different breeds of chickens (Latshaw and Bishop, 2001) and similar breeds of chickens under different management systems. 
To my best knowledge, only one study (Tadele, 2019) has developed prediction equations to estimate the $\mathrm{BW}$ of Ethiopian indigenous chicken populations from body measurements. The author reported a positive and significant $(\mathrm{P}<0.01)$ correlation between $\mathrm{BW}$ and body measurements, including body, wing, back, keel bone and shank lengths as well as chest and shank circumferences for indigenous chickens in the southwestern region of the country. A higher correlation was reported between BW and back length $(r=0.44)$, relative to other measurements. However, the results do not necessarily represent indigenous chicken populations in other rural areas of the country. Understanding the relationship between BW and linear body measurements is of interest not only to develop the prediction equation, but also to use the relationship as a selection criterion in genetic improvement programs aimed at improving indigenous chickens. Thus, the purpose of this study was to analyse the association between BW and four morphometric measurements (body length, chest circumference, shank length, and shank circumference) of indigenous chicken populations under smallholder management conditions in central Ethiopia and to establish prediction equations for estimating $\mathrm{BW}$ from linear body measurements.

\section{Materials and Methods}

\section{Study areas}

Oromia is one of the National Regional States located within Ethiopia. Regional states are further divided into zones and districts (i.e., subdivisions within the zone). Data were generated from indigenous chicken populations reared by smallholder farmers of East Shoa zone (Adama, Bora, and Lume districts) and West Arsi zone (Dodola, Shashemene, and Siriaro districts) of Oromia Regional State, central Ethiopia (Figure 1).

\section{Body Measurements}

Measurements were obtained from a total of 621 matured (i.e., above 8 months) indigenous chickens comprising 134 males and 487 females. The age of the birds was determined using the farmer's "recollecting method". Body weight (g) and linear body measurements (cm) were taken using a hanging spring balance and textile measuring tape, respectively. Body length (BL) was taken as the distance between the tip of the rostrum maxillae (beak) and that of the cauda (tail, without feather). Chest circumference (CC) was measured as the circumference of the body around the deepest region of the breast. Shank length (SL) was the length of the tarsometatarsus measured from the top of the flexed hock joint to the spur of either leg. Shank circumference (SC) was taken as the circumference of the shank around its midway.

\section{Data Preparation}

The whole dataset was randomly partitioned into two samples, namely fitting sample and validation sample. The former, which consisted of 75 percent (114 and 356 records in male and female, respectively) of the whole samples, was used to fit the regression model. The latter, which consisted of 25 percent (20 and 129 observations in male and female, respectively), was used to validate the effectiveness of the model.

\section{Statistical Analysis}

Data were analyzed using SPSS Statistics 20 (IBM SPSS, 2011). Descriptive statistics (mean, SD, minimum, maximum, and coefficient of variation) were used to present the estimates of BW and linear body measurements (BL, CC, SL, and SC) for both male and female birds. Pearson's correlation coefficients (r) were also used to determine the linear relationship between $\mathrm{BW}$ and body measurements. Both descriptive statistics and correlation coefficients were generated using the whole sample. Stepwise multiple linear regression was used to predict BW from body measurements using the fitting sample. The analyses were conducted separately for male and female birds. Prior to the analysis, the data set was assessed to ensure that the assumptions of normality, linearity, multicollinearity, and homoscedasticity are not violated. The model used were:

$$
\mathrm{Y}=\mathrm{b}_{0}+\mathrm{b}_{1} \mathrm{X}_{1}+\mathrm{b}_{2} \mathrm{X}_{2}+\mathrm{b}_{3} \mathrm{X}_{3}+\mathrm{b}_{4} \mathrm{X}_{4}+\mathrm{e}
$$

where, $\mathrm{Y}=\mathrm{BW}, \mathrm{b}_{0}=$ the intercept, $\mathrm{b}_{\mathrm{i}}=$ regression coefficient of $\mathrm{BW}$ on body measurements, $\mathrm{X}_{\mathrm{i}}=$ body measurements (SL, BL, CC, and SC), and e = residual.

Finally, the developed model was applied to the validation sample to evaluate the predictive ability of the multiple regression model. The predictive efficiency of the model was assessed using $R^{2}$ and standard error of the estimate (root mean square error; RMSE).

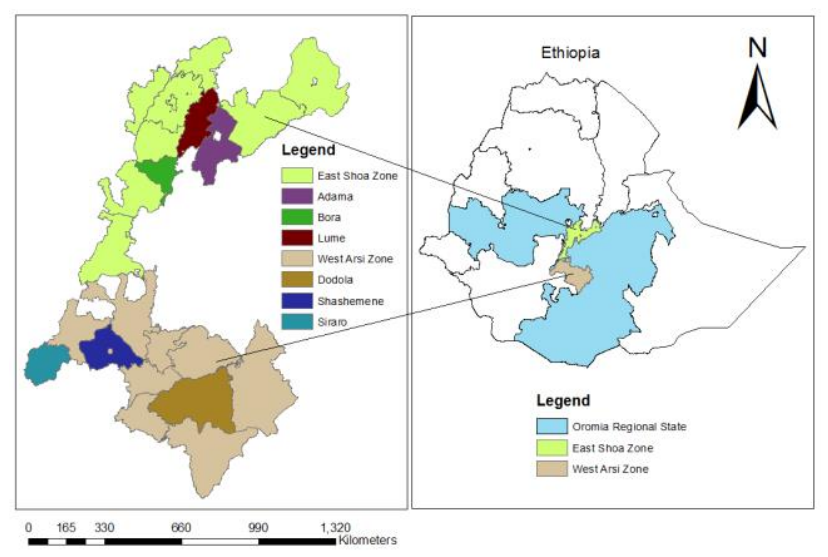

Figure 1. Map of the study location

\section{Results and Discussion}

Table 1 shows the mean, standard deviation (SD), minimum, and maximum values and coefficient of variation $(\mathrm{CV})$ estimates of $\mathrm{BW}$ and linear body measurements (BL, CC, SL, and SC) for both male and female birds. Compared to females, males had significantly higher mean values in all the measurements. On average, a male bird weighed $1267.16 \mathrm{~g}$, while the female weighed 998.76g. Male birds were 21.18 percent heavier than females. This difference suggests the existence of sexual dimorphism, which also accounted for 18.27, 16.17, 8.94, and 6.82 percent of the difference in SL, SC, BL, and CC, respectively. According to Semakula et al. (2011), the observed sexual dimorphism is explained by superior muscle development in males than in females, which is associated with the differences in the level of sex hormone. Sexual size dimorphism (i.e. the difference in sizes of 
males and females) is the result of different selective pressures (Owens and Hartley, 1998). It is also an essential evolutionary attribute that is related to behavior, ecology and life histories of organisms (Remeš and Székely, 2010). Moreover, sexual size dimorphism is usually attributed either to some degree of intra-sexual competition or differences in parental care (Owens and Hartley, 1998). The inter-sexual variation in sizes have also been reported for indigenous chickens (Guèye et al., 1998; Momoh and Kershima, 2008; Semakula et al., 2011; Alabi et al., 2012; Egena et al., 2014), specialized commercial chickens (Latshaw and Bishop, 2001; Abdel-Lattif, 2019), and Muscovy duck (Raji et al., 2009) reared under different management conditions.

The average BW observed in the present study was generally lower than those reported for indigenous chickens of Nigeria (Egena et al., 2014), Uganda (Semakula et al., 2011), South Africa (Alabi et al., 2012) and Senegal (Guèye et al., 1998). The results were also lower than that of Tadele (2019), who reported $1.36 \mathrm{~kg}$ of BW in indigenous chickens (female) of southwestern Ethiopia. However, the average BW in the present study was slightly comparable with that of Tareke et al. (2018), who observed 1.4 and $1.0 \mathrm{~kg}$ of BW, respectively, for male and female chickens of Bale zone, southeastern Ethiopia. This suggests that indigenous chicken populations in the current study area were smaller in size. Smaller body size is believed to play an essential role in reducing the maintenance nutrient requirements and increase feed efficiency (Semakula et al., 2011). According to the same authors, this significantly contributes to the survival of indigenous chickens under the scavenging system, where feed shortage is often a big challenge. For both male and female birds, high variability (CV) was found in BW than linear body measurements, which could reflect environmental and nutritional variations among sampling locations. Compared with morphometric measurements, higher CV was reported in BW for French broiler guinea fowl in the humid tropics of Nigeria (Dzungwe et al., 2018). Generally, the differences within and among the populations could be explained by the variation in genetics, the purpose of chicken rearing in different regions, and environmental factors under which the chickens reared. This variation suggests that indigenous chickens could be used as genetic material in the genetic improvement program aimed to produce breeds adapted to smallholder conditions. The variation in BW of chickens among studies could also be associated with the difference in the age of the birds when measurements were taken.

The relationship between $\mathrm{BW}$ and body measurements (BL, CC, SL, and SC) for both male and female birds was investigated using Pearson's correlation coefficients (Table 2). Correlations between BW and morphometric measurements were generally positive and significant $(p<$ 0.01 ) in both sexes, suggesting that BW could be estimated from one or a combination of these body measurements. In both males and females, the significant $(p<0.01)$ and a strong correlation was found between BW and SL $(r=$ $0.76)$. Body weight was also significantly $(p<0.01)$ and moderately correlated with BL $(r=0.68)$ in females, and SC $(r=0.69)$ and BL $(r=0.67)$ in males. Thus, SL, SC, and $\mathrm{BL}$ could be considered as selection criteria in a breeding program aimed to improve BW in Ethiopian indigenous chickens. Since positive correlations of traits suggest that a single gene influences the traits (i.e., pleiotropy), the relationship between $\mathrm{BW}$ and different morphometric measurements could be useful as a selection criterion (Yakubu, 2009; Malomane et al., 2014). According to Sowande and Sobola (2008), thus, an improvement in any one of the body measurements would result in a corresponding improvement in BW.

The strong correlation between BW and SL has also been observed for indigenous chickens of Nigeria (Ukwu et al., 2014), French broiler guinea fowl in Nigeria (Dzungwe et al., 2018), and naked neck chickens of South Africa (Alabi et al., 2012). On the contrary, BW was strongly correlated with BL $(r=0.87)$ and $\mathrm{CC}(r=0.85)$ in Muscovy duck (Raji et al., 2009), SC in Venda and Potchefstroom koekoek chickens of South Africa (Alabi et al., 2012), and BL in Nigerian indigenous chickens (Egena et al., 2014). Semakula et al. (2011) also observed that CC was the best single predictor $(r=0.88)$ of BW, closely followed by BL $(r=0.81)$, and femur length $(r=0.80)$ for indigenous chickens in Uganda. Slightly higher correlation coefficients were observed in males than females. According to Alabi et al. (2012), this implies that more improvement will be expected for the traits in male birds than female birds. These results were also supported by $R^{2}$ values (Table 5), where slightly higher variations for the traits were observed in males than females.

Table 1. Descriptive statistical summary of body weight and linear body measurements of indigenous chickens using the whole sample.

\begin{tabular}{c|lccccc}
\hline \multicolumn{1}{c}{ Variables } & \multicolumn{1}{c}{ Sex } & Mean & SD & Minimum & Maximum & CV $(\%)$ \\
\hline \multirow{2}{*}{ BW $(\mathrm{g})$} & Male & $1267.16^{\mathrm{a}}$ & 402.21 & 600.00 & 2500.00 & 31.74 \\
& Female & $998.76^{\mathrm{b}}$ & 342.93 & 500.00 & 2400.00 & 34.34 \\
\hline \multirow{2}{*}{$\mathrm{BL}(\mathrm{cm})$} & Male & $37.69^{\mathrm{a}}$ & 2.79 & 31.00 & 44.00 & 7.40 \\
& Female & $34.32^{\mathrm{b}}$ & 2.32 & 28.00 & 42.00 & 6.76 \\
\hline \multirow{2}{*}{$\mathrm{CC}(\mathrm{cm})$} & Male & $27.70^{\mathrm{a}}$ & 2.63 & 21.00 & 36.00 & 9.51 \\
& Female & $25.81^{\mathrm{b}}$ & 2.08 & 19.00 & 33.00 & 8.05 \\
\hline \multirow{2}{*}{$\mathrm{SL}(\mathrm{cm})$} & Male & $9.36^{\mathrm{a}}$ & 1.31 & 7.00 & 12.00 & 13.95 \\
& Female & $7.65^{\mathrm{b}}$ & 1.01 & 5.00 & 11.00 & 13.23 \\
\hline \multirow{2}{*}{$\mathrm{SC}(\mathrm{cm})$} & Male & $4.33^{\mathrm{a}}$ & 0.72 & 3.00 & 8.00 & 16.63 \\
& Female & $3.63^{\mathrm{b}}$ & 0.57 & 3.00 & 6.00 & 15.68 \\
\hline
\end{tabular}

Means with different superscript differ significantly between sexes; $\mathrm{SD}=$ Standard deviation, $\mathrm{CV}=\mathrm{Coefficient}$ of variation, $\mathrm{BW}=\mathrm{Body}$ weight, $\mathrm{BL}=$ Body length, $\mathrm{CC}=$ Chest circumference, $\mathrm{SL}=$ Shank length, and $\mathrm{SC}=$ Shank circumference. 
Table 2. Pearson's correlations between BW and body measurements of male birds (above diagonal) and female birds (below diagonal) using the whole samples.

\begin{tabular}{l|ccccc}
\hline & BW & BL & CC & SL & SC \\
\hline BW & 1.00 & $0.67^{* *}$ & $0.52^{* *}$ & $0.76^{* *}$ & $0.69^{* *}$ \\
BL & $0.68^{* *}$ & 1.00 & $0.53^{* *}$ & $0.60^{* *}$ & $0.52^{* *}$ \\
CC & $0.29^{* *}$ & $0.33^{* *}$ & 1.00 & $0.29^{* *}$ & $0.36^{* *}$ \\
SL & $0.76^{* *}$ & $0.66^{* *}$ & $0.05^{\mathrm{NS}}$ & 1.00 & $0.67^{* *}$ \\
SC & $0.59^{* *}$ & $0.48^{* *}$ & $0.03^{\mathrm{NS}}$ & $0.65^{* *}$ & 1.00 \\
\hline
\end{tabular}

** Correlation is significant at 0.01 (2-tailed); NS $=$ Not significant, $\mathrm{BW}=$ Body weight, $\mathrm{BL}=$ Body length, $\mathrm{CC}=\mathrm{Chest}$ circumference, $\mathrm{SL}=\mathrm{Shank}$ length, and $\mathrm{SC}=$ Shank circumference.

Table 3. Stepwise regression analysis summary for each of the independent variables (or predictors) included in the model for male birds.

\begin{tabular}{l|lcccccc}
\hline \multicolumn{1}{c}{ Model } & Predictors & B & SE & Beta & P-value & Tolerance & VIF \\
\hline \multirow{2}{*}{1} & Constant & -911.588 & 175.673 & & 0.000 & & 1.000 \\
& SL & 232.223 & 18.679 & 0.764 & 0.000 & 1.000 \\
\hline \multirow{3}{*}{3} & Constant & -1966.014 & 256.850 & & 0.000 & & \\
& SL & 212.168 & 17.275 & 0.698 & 0.000 & 0.949 & 1.054 \\
& CC & 45.022 & 8.745 & 0.293 & 0.000 & 0.949 & 1.054 \\
\hline \multirow{3}{*}{4} & Constant & -265.891 & 242.263 & & 0.000 & & 1.899 \\
& SL & 147.419 & 21.345 & 0.485 & 0.000 & 0.527 & 1.058 \\
& CC & 42.633 & 8.066 & 0.277 & 0.000 & 0.945 & 1.877 \\
& SC & 204.455 & 44.967 & 0.318 & 0.001 & 0.533 & \\
& Constant & -2585.933 & 285.932 & & 0.000 & & \\
& SL & 122.043 & 22.968 & 0.402 & 0.000 & 0.432 & 2.316 \\
& CC & 31.690 & 8.913 & 0.206 & 0.001 & 0.735 & 1.361 \\
& SC & 191.062 & 44.112 & 0.297 & 0.000 & 0.525 & 1.903 \\
& BL & 27.061 & 10.397 & 0.187 & 0.011 & 0.480 & 2.084 \\
\hline
\end{tabular}

$\mathrm{B}=$ Unstandardized coefficients, Beta $=$ Standardized coefficients, SE = Standard error of coefficients, $p$-value $=$ Significant level, VIF $=$ Variance inflation factor, $\mathrm{BL}=$ Body length, $\mathrm{CC}=$ Chest circumference, $\mathrm{SL}=$ Shank length, and $\mathrm{SC}=$ Shank circumference.

Table 4. Stepwise regression analysis summary for each of the independent variables (or predictors) included in the model for female birds.

\begin{tabular}{|c|c|c|c|c|c|c|c|}
\hline Model & Predictors & B & SE & Beta & P-value & Tolerance & VIF \\
\hline \multirow{2}{*}{1} & Constant & -1052.148 & 91.567 & & 0.000 & & \\
\hline & SL & 269.142 & 11.854 & 0.770 & 0.000 & 1.000 & 1.000 \\
\hline \multirow{3}{*}{2} & Constant & -2163.142 & 162.300 & & 0.000 & & \\
\hline & SL & 192.574 & 14.509 & 0.551 & 0.000 & 0.566 & 1.766 \\
\hline & $\mathrm{BL}$ & 49.331 & 6.157 & 0.333 & 0.000 & 0.566 & 1.766 \\
\hline \multirow{4}{*}{3} & Constant & -2514.733 & 174.856 & & 0.000 & & \\
\hline & SL & 208.036 & 14.486 & 0.596 & 0.000 & 0.536 & 1.864 \\
\hline & $\mathrm{BL}$ & 36.650 & 6.574 & 0.247 & 0.000 & 0.469 & 2.132 \\
\hline & $\mathrm{CC}$ & 26.005 & 5.582 & 0.156 & 0.000 & 0.824 & 1.214 \\
\hline \multirow{5}{*}{4} & Constant & -2569.225 & 173.630 & & 0.000 & & \\
\hline & $\mathrm{SL}$ & 183.434 & 16.357 & 0.525 & 0.000 & 0.411 & 2.435 \\
\hline & $\mathrm{BL}$ & 35.050 & 6.515 & 0.236 & 0.000 & 0.466 & 2.145 \\
\hline & $\mathrm{CC}$ & 27.118 & 5.527 & 0.163 & 0.000 & 0.820 & 1.219 \\
\hline & $\mathrm{SC}$ & 73.880 & 23.788 & 0.121 & 0.002 & 0.591 & 1.691 \\
\hline
\end{tabular}

$\mathrm{B}=$ Unstandardized coefficients, Beta $=$ Standardized coefficients, SE $=$ Standard error of coefficients, $p$-value $=$ Significant level, VIF $=$ Variance inflation factor, $\mathrm{BL}=$ Body length, $\mathrm{CC}=$ Chest circumference, $\mathrm{SL}=$ Shank length, and $\mathrm{SC}=\mathrm{Shank}$ circumference.

Table 5. Linear regression equations for estimation of BW from linear body measurements using fitting sample

\begin{tabular}{|c|c|c|c|c|}
\hline Model & Prediction equation & P-value & $\mathrm{R}^{2}$ & RMSE \\
\hline \multicolumn{5}{|c|}{ Male } \\
\hline 1 & $\mathrm{BW}=-911.59+232.22(\mathrm{SL})$ & $<0.001$ & 0.58 & 254.94 \\
\hline 2 & $\mathrm{BW}=-1966.01+212.17(\mathrm{SL})+45.02(\mathrm{CC})$ & $<0.001$ & 0.67 & 229.70 \\
\hline 3 & $\mathrm{BW}=-2165.89+147.42(\mathrm{SL})+42.63(\mathrm{CC})+204.46(\mathrm{SC})$ & $<0.001$ & 0.72 & 211.41 \\
\hline 4 & $\mathrm{BW}=-2585.93+122.04(\mathrm{SL})+31.69(\mathrm{CC})+191.06(\mathrm{SC})+27.06(\mathrm{BL})$ & $<0.001$ & 0.74 & 205.98 \\
\hline \multicolumn{5}{|c|}{ Female } \\
\hline 1 & $\mathrm{BW}=-1052.15+269.14(\mathrm{SL})$ & $<0.001$ & 0.59 & 224.10 \\
\hline 2 & $\mathrm{BW}=-2163.14+192.57(\mathrm{SL})+49.33(\mathrm{BL})$ & $<0.001$ & 0.66 & 206.38 \\
\hline 3 & $\mathrm{BW}=-2514.73+208.04(\mathrm{SL})+36.65(\mathrm{BL})+26.01(\mathrm{CC})$ & $<0.001$ & 0.68 & 200.57 \\
\hline 4 & $\mathrm{BW}=-2569.23+183.43(\mathrm{SL})+35.05(\mathrm{BL})+27.12(\mathrm{CC})+73.88(\mathrm{SC})$ & $<0.001$ & 0.69 & 198.15 \\
\hline
\end{tabular}

$R^{2}=$ Coefficient of determination, $p$-value $=$ Significant level, RMSE $=$ Root mean square error, $\mathrm{BW}=$ Body weight, $\mathrm{BL}=\mathrm{Body}$ length, $\mathrm{CC}=\mathrm{Chest}$ circumference, $\mathrm{SL}=$ Shank length, and $\mathrm{SC}=$ Shank circumference. 
Table 6. Evaluating the performance of multiple regression analysis using fitting and validation samples.

\begin{tabular}{|c|c|c|}
\hline & Fitting sample & Validation sample \\
\hline \multicolumn{3}{|c|}{ Male } \\
\hline Number of records & 114 & 20 \\
\hline RMSE & 205.978 & 239.440 \\
\hline $\mathrm{R}^{2}$ & 0.736 & 0.775 \\
\hline Adjusted $\mathrm{R}^{2}$ & 0.726 & 0.716 \\
\hline Correlation coefficient & $0.858 * *$ & $0.880 * *$ \\
\hline \multicolumn{3}{|c|}{ Female } \\
\hline Number of records & 356 & 129 \\
\hline RMSE & 198.146 & 182.049 \\
\hline $\mathrm{R}^{2}$ & 0.685 & 0.685 \\
\hline Adjusted $\mathrm{R}^{2}$ & 0.681 & 0.674 \\
\hline Correlation coefficient & $0.828 * *$ & $0.828 * *$ \\
\hline
\end{tabular}

The stepwise regression summary for each of the predictors (BL, CC, SL, and SC) is indicated for both males (Table 3) and females (Table 4). The collinearity problem on each variable was diagnosed using tolerance and its reciprocal, called the variance inflation factor (VIF). If tolerance, a value which indicates how much of the variability of a specific predictor is not explained by the other predictors in the model, is below 0.10 , it indicates that the variable has high correlations with other variables (Pallant, 2011). This suggests the possibility of multicollinearity (i.e., high inter-associations among independent variables). In the present study, the tolerance value was found in the range of 0.43 and 1.00 in males and 0.41 and 1.00 in females, which is above the cutoff point. This was also supported by the VIF values, ranging from 1.00 to 2.32 in males and from 1.00 to 2.44 in females, which are well below the recommended value. VIF value above 10 is regarded as indicating multicollinearity.

A model was developed to predict $\mathrm{BW}$ from morphometric measurements (BL, CC, SL, and SC) for both male and female birds using the coefficients of the predictors (Table 5). Since BW is highly dependent on growth (Alabi et al., 2012), the predictive equations developed in the present study showed that BW could be estimated from most morphometric measurements. Among the four body measurements, SL best predicted BW in both sexes, with coefficients of determination $\left(R^{2}\right)$ equals 0.58 in males and 0.59 in females. This indicates that nearly 60 percent of the variance in BW was explained by SL thus this body measurement could be used as a single most important predictor of BW. Similar observations were reported in Nigerian indigenous chickens (Ukwu et al., 2014), and Japanese quail (Gambo et al., 2014). A combination of SL with one or more of other measurements (BL, CC, and SC) generally improved the predictive power of the equations. When SL was combined with $\mathrm{CC}, R^{2}$ increased to 0.67 in male birds. In female birds, however, the combination SL and BL best predicted $\mathrm{BW}$, with $R^{2}=0.66$. If possible combinations of additional measurements were considered, the combinations that included SL, CC, and SC best predicted BW in male $\left(R^{2}=\right.$ 0.72 ) and combinations that included SL, BL, and CC in female $\left(R^{2}=0.68\right)$ birds. If all the measurements of $\mathrm{BL}$, CC, SL, and SC were included, $R^{2}$ increased to 0.74 and 0.69 , respectively, in male and female birds. Thus, a model that combines all four measurements could be best in accurately predicting BW in the studied chicken populations. This agrees with the conclusion of Latshaw and Bishop (2001), who implied that the predictive power of the equations was improved when more measurements are included. Likewise, Adeyinka and Mohammed (2006) concluded that multiple regression equations could accurately predict $\mathrm{BW}$ in goat than prediction equations with a single measurement.

The standardized coefficient (Beta) indicates which of the variables included in the model contributed to the prediction of the dependent variable (Pallant, 2011). Each of the independent variables included in the model significantly contributed to the prediction of the dependent variable with $p$-value ranging from $<0.0001$ to 0.015 (Tables 3 and 4). In models that included more than two measurements, SL makes the strongest unique contribution in predicting BW for both male and female birds. For instance, in model 4 , the largest beta coefficients were 0.40 and 0.53 for SL in males and females, respectively. On the contrary, the Beta values for BL, CC, and SC were much lower than SL, indicates that they made less of a contribution in predicting $\mathrm{BW}$. The standardized beta coefficient values obtained can also be used for more practical interpretations than the theoretical model testing from a genetic improvement point of view. According to Pallant (2011), these values indicate the number of standard deviations in the dependent variable would change if there was a one standard deviation unit change in the predictor. In model 1, for instance, if SL could increase by one standard deviation, BW would likely be raised by 0.76 and 0.77 standard deviation units in male and female birds, respectively.

Table 6 summarizes accuracy of the fitted models to predict BW from linear body measurements. Although slightly higher RMSE value was recorded in validation sample (239.44) compared to fitting sample (205.98), the prediction accuracy was increased from 74 percent in fitting sample to 78 percent in validation sample in male birds. In female, both fitting and validation samples showed similar prediction efficiency with $R^{2}=0.69$. However, slightly lower RMSE value was recorded for validation sample (182.05) than for fitting sample (198.15). The results generally suggest that fitting the multiple regression model to the validation sample can effectively predict BW in indigenous chickens in Ethiopia from their linear body measurements. 


\section{Conclusion}

The positive and significant correlation between BW and morphometric measurements suggests that these measurements can be used as a selection criterion in the genetic improvement of Ethiopia indigenous chicken populations. The stepwise regression results also indicate that $\mathrm{BW}$ of these chickens can be predicted from morphometric measurements, especially SL. Although SL is the best single predictor of BW than other morphometric measurements, combining it with one or more body measurements improved the accuracy of the prediction equation. Thus, the choice of the optimal equation may depend on the body measurements that are easy to take and practical under the on-farm condition. Under smallholder management conditions, where the weighing balance may not be readily available, a simple measuring tape can be used to estimate BW of Ethiopia indigenous chickens using the developed prediction equations.

\section{References}

Abdel-Lattif FH. 2019. The linear association between live body weight and some body measurements in some chicken strains. Plant Archives, 19: 595-599.

Adeyinka IA, Mohammed ID. 2006. Accuracy of body weight prediction in Nigerian red Sokoto goats raised in North Eastern Nigeria using linear body measurement. Pakistan Journal of Biological Sciences, 9: 2828-2830. DOI: 10.3923/pjbs.2006.2828.2830.

Alabi OJ, Ng'ambi JW, Norris D, Egena SSA. 2012. Comparative study of three indigenous chicken breeds of South Africa: Body weight and linear body measurements. Agricultural Journal, 7: 220-225. DOI: 10.3923/aj.2012.220.225.

Assan N. 2013. Bioprediction of body weight and carcass parameters from morphometric measurements in livestock and poultry. Scientific Journal of Review, 2: 140-150.

Deribe B, Beyene D, Dagne K, Getachew T, Gizaw S. 2018. Predicting body weight of three Ethiopian thin-tailed sheep breeds from linear body measurements. Journal of Natural Sciences Research, 8: 25-32.

Dzungwe JT, Gwaza DS, Egahi JO. 2018. Statistical modeling of body weight and body linear measurements of the French broiler guinea fowl in the humid tropics of Nigeria. Poultry, Fisheries and Wildlife Sciences, 6: 2. DOI: 10.4172/2375446X.1000197.

Egena SSA, Ijaiya AT, Kolawole R. 2014. An assessment of the relationship between body weight and body measurements of indigenous Nigeria chickens (Gallus gallus domesticus) using path coefficient analysis. Livestock Research for Rural Development, 26 (3).

Gambo D, Momoh OM, Dim NI, Kosshak AS. 2014. Body parameters and prediction of body weight from linear body measurements in Coturnix quail. Livestock Research for Rural Development, 26 (6).

Guèye EF, Ndiaye A, Branckaert RDS. 1998. Prediction of body weight on the basis of body measurements in mature indigenous chickens in Senegal. Livestock Research for Rural Development, 10 (3).

IBM SPSS (Statistical Packages for the Social Sciences). 2011. IBM SPSS Statistics for Windows Version 20.0. Armonk, NY: IBM Corp.
Latshaw JD, Bishop BL. 2001. Estimating body weight and body composition of chickens by using non-invasive measurements. Poultry Science, 80: 868-873. DOI: 10.1093/ps/80.7.868.

Lukuyu MN, Gibson JP, Savage DB, Duncan AJ, Mujibi FDN, Okeyo AM. 2016. Use of body linear measurements to estimate live weight of crossbred dairy cattle in smallholder farms in Kenya. SpringerPlus, 5: 63. DOI: 10.1186/s40064016-1698-3.

Malomane DK, Norris D, Banga CB, Ngambi JW. 2014. Use of factor scores for predicting body weight from linear body measurements in three South African indigenous chicken breeds. Tropical Animal Health and Production, 46: 331-335. DOI: $10.1007 / \mathrm{s} 11250-013-0492-2$.

Momoh OM, Kershima DE. 2008. Linear body measurements as predictors of body weight in Nigerian local chickens. ASSET Series A, 8: 206-212.

Owens IPF, Hartley IR. 1998. Sexual dimorphism in birds: Why are there so many different forms of dimorphism? Proceedings of the Royal Society B: Biological Sciences, 265: 397-407. DOI: 10.1098/rspb.1998.0308.

Pallant J. 2011. SPSS Survival Manual. A Step by Step Guide to Data Analysis Using SPSS. 4th ed. Australia: Allen and Unwin. ISBN 978-1-74237-392-8.

Raji AO, Igwebuike JU, Usman MT. 2009. Zoometrical body measurements and their relation with live weight in matured local Muscovy ducks in Borno state Nigeria. ARPN Journal of Agricultural and Biological Science, 4: 58-62.

Remeš V, Székely T. 2010. Domestic chickens defy Rensch's rule: Sexual size dimorphism in chicken breeds. Journal of Evolutionary Biology, 23: 2754-2759. DOI: 10.1111/j.14209101.2010.02126.x.

Semakula J, Lusembo P, Kugonza DR, Mutetikka D, Ssennyonjo J, Mwesigwa M. 2011. Estimation of live body weight using zoometrical measurements for improved marketing of indigenous chicken in the Lake Victoria basin of Uganda. Livestock Research for Rural Development, 23 (8).

Sowande OS, Sobola OS. 2008. Body measurements of West African dwarf sheep as parameters for estimation of live weight. Tropical Animal Health and Production, 40: 433439. DOI: $10.1007 / \mathrm{s} 11250-007-9116-\mathrm{z}$.

Tadele A. 2019. Statistical modelling of indigenous chicken with body weight and linear body measurements in Bench Maji Zone, South Western Ethiopia. International Journal of Environmental Sciences and Natural Resources, 22: 63-67. DOI: 10.19080/IJESNR.2019.22.556083.

Tareke M, Assefa B, Abate T, Tekletsadik E. 2018. Evaluation of morphometric differences among indigenous chicken populations in Bale zone, Oromia Regional State, Ethiopia. Poultry Science Journal, 6: 181-190. DOI: 10.22069/psj.2018.14974.1329.

Ukwu HO, Okoro VMO, Nosike RJ. 2014. Statistical modelling of body weight and linear body measurements in Nigerian indigenous chicken. IOSR Journal of Agriculture and Veterinary Science, 7: 27-30. DOI: 10.9790/2380-07152730.

Yakubu A. 2009. Fixing collinearity instability in the estimation of body weight from morpho-biometrical traits of West African dwarf goats. Trakia Journal of Sciences, 7: 61-66. 